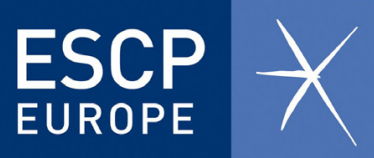

\title{
Impact of M\&As on organizational performance: The moderating role of HRM centrality
}

\author{
Manuela Faia Correia ${ }^{a}$, Rita Campos e Cunha ${ }^{b, *}$, Marc Scholten ${ }^{c}$
}

\author{
a Lusiada University, Rua da Junqueira, 188-198, 1349-001 Lisboa, Portugal \\ ${ }^{b}$ Nova School of Business and Economics, R. Marques de Fronteira 20, 1099-038 Lisboa, Portugal \\ c ISPA University Institute, Rua Jardim do Tabaco 34, 1149-041 Lisboa, Portugal
}

\section{KEYWORDS}

Mergers and acquisi-

tions;

Human resource management centrality; Organizational performance

\begin{abstract}
Summary In this study, we examine how the effects of mergers and acquisitions on organizational performance are moderated by human resource management (HRM) centrality. We differentiate three types of ownership change: mergers, bidder, and target acquisitions. The study is anchored on the literatures addressing strategic human resource management and strategic contingencies of intra-organizational power. In an analysis of the data from the 2005 Cranet survey, results showed that (i) formalization attenuated a positive impact of bidder acquisitions and aggravated a negative impact of mergers on performance, but (ii) HRM strategic involvement and centralization of HRM practices boosted a positive impact of bidder acquisitions on performance. The study offers new insights about the role of HRM centrality, and suggests that mergers and acquisitions should be studied as differentiated ownership change processes.
\end{abstract}

(c) 2013 Elsevier Ltd. All rights reserved.

\section{Introduction}

Mergers and acquisitions (M\&A) are popular forms of organizational change. Despite their popularity, however, they appear to yield mixed results (Agrawal \& Jaffe, 2003; Cartwright \& Schoenberg, 2006; King, Dalton, Daily, \& Covin, 2004). This has been attributed to a variety of factors, including culture gaps and clashes, and incompatibility between, and loss of, key people (Bianco, 2000; Fairlamb, John, \& Thornton, 2000). Executives who have been through processes of ownership change now recognize that the management of the human side is the real key to maximizing the value of a deal (Gunther, 2001; Kay \& Shelton, 2000) and ex-

\footnotetext{
* Corresponding author. Tel.: +351 965059715; fax: +351 213873973.

E-mail address: rcunha@novasbe.pt (R.C. Cunha).
}

pect a proactive management of the human integration process to lead to a situation where both organizations win (Cartwright \& Cooper, 1996).

Although it is believed that HRM can contribute to the success of M\&A, there is a surprising lack of evidence to corroborate this view. In this study, we examine how HRM centrality affects the relation between ownership change and performance. HRM centrality corresponds to the status of HRM as a function in the organization, i.e., a combination of the perceived power of the HR department as an agent of integration, through the existence of formal strategies and the strategic involvement of HRM in the change process, as well as the centralized responsibility for HR practices.

The components of our analysis are ownership change (bidder acquisition, target acquisition and merger), HRM centrality, and organizational performance. With this work, 
we contribute to the field of HRM by examining the role of HRM centrality in moderating the relation between mergers or acquisitions and organizational performance, and by exploring how the moderating effect itself depends on the type of ownership change involved.

The paper is structured as follows: we first discuss the literature on the relationships between HRM, mergers and acquisitions and organizational performance. We then present the research model and our hypotheses. Subsequently, we describe the research method, and present the statistical analyses and results. We conclude by discussing the findings and their implications.

\section{Theoretical background and hypotheses}

Two core principles in the SHRM literature are: the importance given to the integration of HRM into the business and corporate strategy, and the devolvement of HRM to line managers instead of personnel specialists. Integration was defined as "the degree to which HRM issues are considered as part of the formulation of the business strategy" and devolvement as "the degree to which HRM practices involve and give responsibility to line managers rather than personnel specialists"' (Brewster \& Larsen, 1992, p. 411-412). SHRM literature has additionally emphasized the importance of HR strategy implementation and execution, which has been accompanied by a growing interest in relating HRM activities to competitive performance (see Lengnick-Hall, Lengnick-Hall, Andrade, \& Drake, 2009, for an extensive review of the evolution of SHRM).

When companies merge or acquire/are acquired by, other companies, corporate strategy is the main driver of decision making, either to achieve economies of scale, to expand their market and internationalize, to spread their risk, to respond to radical changes in the industry and to improve efficiency and flexibility (Kumar, 2009; Schuler \& Jackson, 2001).

However, the literature on the impact of M\&As on organizational performance provides mixed results. Research in the finance area has focused on the creation of wealth to companies involved in M\&As. Meta-analytical studies (Datta, Narayanan, \& Pinches, 1992; King et al., 2004) show that positive results are obtained for target acquisition companies, and not for merging and bidder acquisition companies, but all lose when the mode of payment involves stock financed transactions, instead of cash. These are, however, short-term stock-market events studies, and when accounting measures were used (King et al., 2004) no significant or positive results were found. These findings notwithstanding, the level of mergers and acquisitions has not decreased, which suggests that these studies have not been "looking at 'the right' set of variables as predictors of post-acquisition performance'" (King et al., 2004, p. 197).

In the management literature, research has shown that M\&As' impact on organizational performance fails to live up to expectations, for reasons associated with HRM and employment issues being poorly handled (Buono \& Bowditch, 1989; Cartwright \& Cooper, 1996; DeNisi \& Shin, 2004; Reeves \& Edwards, 2009; Stahl, Mendenhall, \& Weber, 2005; Weber \& Drori, 2008).

\subsection{The moderating role of human resource management centrality}

Effects of M\&As on both employees and managers, on corporate culture integration and on systems alignment suggest the integration of human resource management policies and practices as a potential contributor to company postacquisition performance.

Although the link between HRM and organizational performance has been demonstrated by the SHRM literature, Guest (2011) argues that studies to date do not reveal how this association works, or even the direction of the relationship, which suggests focusing on some process issues, such as HRM legitimacy, consistency and relative power that may create strong HRM systems (Bowen \& Ostroff, 2004).

M\&As are major organizational life events that generate great internal turbulence and causal ambiguity (Cording, Christmann, \& King, 2008; Lakshman, 2011). This causal ambiguity is present not only at the interfirm level, due to cultural differences that may hinder knowledge transfer in the post-acquisition stage, but also at the intrafirm level, particularly among middle managers who are the major strategy implementers (Lakshman, 2011), and lower level employees, who fear for their career development and, ultimately, for the continuation of their employment. It is only natural that successful human integration in processes of ownership change will require HRM to play a more central and strategic role in their organizations (Björkman \& Söderberg, 2003), namely in establishing systems to promote trust among organizational actors in the merging firms and to create an organizational architecture of human resource practices that ensure motivation to cultural integration, in terms of rewards, performance management, skills development, staffing, industrial relations and workforce reduction.

The HRM function should be strategically involved in the early stages of the integration process (Lakshman, 2011) in order to capture the complementary capabilities of the companies and therefore create the conditions for the aimed synergies to be accomplished.

Besides, and based on the SHRM literature, HRM must be strategically coordinated in order to play its positive role (Combs, Yongmei, Hall, \& Ketchen, 2006; Delery, 1998; MacDuffie, 1995) and emphasis needs to be placed on the implementation process, so that firms create strong HRM Systems (Bowen \& Ostroff, 2004). This, in turn, requires that corporate and HRM strategies should be formalized, which can increase the ability to cope with uncertainty.

Additionally, according to Danya, Guedrib, and Hatta (2008), performance is better when influence over HRM issues is shared by HRM specialists and line managers (LMs), except when there are major organizational changes, in which case the HRM specialists' role should predominate in order to overcome the potential lack of interest, time and competences of LMs in HRM issues, themselves overloaded by the extra responsibilities demanded by the change process. The primary responsibility for various HRM areas should then be centralized with HRM specialists, who should be involved in the design and implementation of HRM policies and practices from the outset. 
The three conditions above mean that HRM should have an increased intraorganizational power by assuming a central, strategically integrated role in cases of M\&As (Hickson, Hinings, Lee, Schneck, \& Pennings, 1971; Hinings, Hickson, Pennings, \& Schneck, 1974). HR centrality has traditionally been used in the literature (Becker \& Gerhart, 1996; Nikandrou \& Papalexandris, 2007; Tregaskis, 1997) as composed by the concepts of HR involvement in corporate strategy and the existence of HR strategy, to which we added the centralization of HR practices. In case of major organizational changes in order to promote cultural integration and strong HRM systems the centralization of HR practices by the HRM department is required. Hence, we consider HRM centrality to be a tridimensional construct comprising: the involvement of HRM in the strategic decisions from the outset (strategic involvement), formalized corporate and HR strategies (formalization), and centralization of HR practices in the HRM department (HRM practices centralization), in order to create strategically consistent support to the integration process of the merging or acquisition partners.

The integration process, however, may take different paths, in terms of the desired cultural end-state (Marks \& Mirvis, 2011; Weber \& Tarba, 2010). We distinguish three types of ownership change: bidder acquisition, i.e., buying another organization, target acquisition, i.e., being bought by another organization, and merger, i.e., fusing two organizations (Schuler \& Jackson, 2001). According to Marks and Mirvis $(2001,2011)$ the level of change differs according to the degree of integration expected for the combining organizations: (i) preservation, in which the acquired company retains most of its autonomy, (ii) absorption, when the acquired company adjusts to the acquirer's way of doing business and tends to cultural assimilation, (iii) reverse merger, i.e., the acquired company culturally absorbs the acquiring company, (iv) best of both, sometimes called a 'merger of equals', in which a partial or full integration of best practices from both sides is to be achieved and (v) transformation, when both companies look for a deep break with their past practices and culture to create a different organization.

HRM centrality can be expected to differ according to the type of pursued integration strategy. We may expect that in mergers, either 'best of both' or 'transformation' types of integration will be more common, because two companies are fusing, and maintaining balance in HRM issues such as layoffs or work practices is important in the integration stage, to cope with culture differences and develop a new identity (Drori, Wrzesniewski, \& Ellis, 2011).

In acquisitions, on the other hand, the 'absorption' strategy may be expected to predominate, the bidder companies imposing their working methods to the target acquisition companies.

We expect that HRM centrality will moderate the relationship between the processes of ownership change and organizational performance, by creating mechanisms to reduce the ambiguity that surrounds ownership change for the employees and managerial staff and therefore enhancing motivation to successfully integrate the two organizations. However, the moderating effect of the three facets of HRM Centrality - formalization, HRM strategic involvement and centralization of HRM practices in the HRM department - will be different, according to type of ownership change.
Our first hypothesis concerns the level of strategic involvement of HRM. As mentioned above, early involvement is needed to identify and maximize complementary capabilities and their interdependencies (Lakshman, 2011). We expect early HRM strategic involvement to improve the impact of ownership change on performance.

H1. HRM strategic involvement in the M\&A decision making moderates the impact of M\&As on organizational performance:

H1.a) In the case of merging companies, HRM strategic involvement will positively moderate the impact of the merger process on organizational performance;

H1.b) In the case of bidder acquisition companies, HRM strategic involvement will positively moderate the impact of the acquisition process on organizational performance;

H1.c) In the case of target acquisition companies, HRM strategic involvement will positively moderate the impact of the acquisition process on organizational performance.

Our second hypothesis concerns level of formalization. In the case of mergers, given that both companies will need to integrate practices, while respecting the cultural differences between them (Drori, Wrzesniewski, \& Ellis, 2011), formalization may negatively moderate the relationship between ownership change and performance, whereas in the case of acquisitions, we expect that formalization will enhance the impact of change on performance. Hence:

H2. Formalization moderates the impact of M\&As on organizational performance:

H2.a) In the case of merging companies, formalization will negatively moderate the impact of the merger process on organizational performance.

H2.b) In the case of bidder acquisition companies, formalization will positively moderate the impact of the acquisition process on organizational performance.

H2.c) In the case of target acquisition companies, formalization will positively moderate the impact of the acquisition process on organizational performance.

Our third hypothesis relates to the degree to which HRM practices are centralized at the HRM Department, instead of being devolved to line managers. As pointed out, influence over HRM issues is expected to be shared by the HRM department and line managers, except in cases of major change ( $\mathrm{Da}$ nya et al., 2008). We therefore consider that centralizing HRM practices in the HRM department, instead of devolving them to line managers, will have a positive moderating impact in all types of ownership change.

H3. HRM practices centralization in the HRM Department moderates the impact of M\&As on organizational performance: 
H3.a) In the case of merging companies, HRM practices centralization in the HRM Department will positively moderate the impact of the merger process on organizational performance.

H3.b) In the case of bidder acquisition companies, HRM practices centralization in the HRM Department will positively moderate the impact of the acquisition process on organizational performance.

H3.c) In the case of target acquisition companies, HRM practices centralization in the HRM Department will positively moderate the impact of the acquisition process on organizational performance.

\section{Research model}

Most studies that examined the role of HRM in M\&As have used case studies or domestic surveys (e.g., Antila, 2006; Björkman \& Söderberg, 2003; Clement \& Greenspan, 2000; Drori et al., 2011), treated mergers and acquisitions indiscriminately and used few indicators of organizational performance (for exceptions, see Danya et al., 2008; Nikandrou \& Papalexandris, 2007). We overcome those limitations with our research model, presented in Fig. 1. The different types of ownership change processes are considered in the analyses of a large sample of companies.

\section{Methodology}

\subsection{Survey and sample}

This study draws on the 2005 Cranet survey containing data on HR policies and practices in private and public sector organizations in 32 countries, mostly European. The survey asks the most senior HRM professional (self-assessment) a range of questions on company policies and practices in human resource management, covering the personnel function, staffing, employee development, compensation and benefits, employee's relations and communication, and organizational details (Brewster, Mayrhofer, \& Morley, 2004). The sample comprises a total of 6768 usable questionnaires, gathered over a period of 18 months, from late 2003 to mid-2005. Tables 1 and 2 present a description of the sample. Table 1 presents the distribution of the sample by their reported histories of change and Table 2 provides the distribution of the companies that experienced change by industrial sector.

\subsection{Measures}

Ownership change was composed of three binary variables relating to mergers, bidder acquisitions, and target acquisitions, and indicating whether an organization had gone through a particular change (1) or not $(0)$, in the last 3 years.

HRM centrality was composed of three interrelated, but distinct, variables: (1) HRM strategic involvement, (2) Formalization, and (3) Centralization of HRM practices. In terms of HRM strategic involvement, we distinguished four levels: HRM strategic involvement from the outset (3), HRM strategic involvement through consultation (2), HRM strategic involvement on implementation (1), and HRM not consulted $(0)$. Concerning formalization, we distinguished written formalization, unwritten formalization, and no formalization in two areas - business strategy and personnel/HRM strategy. The coding was done as shown in Table 3.

Finally, the centralization of HRM practices in the HRM Department includes five areas: pay and benefits, recruitment and selection, training and development, industrial relations, and workforce expansion/reduction. We considered whether

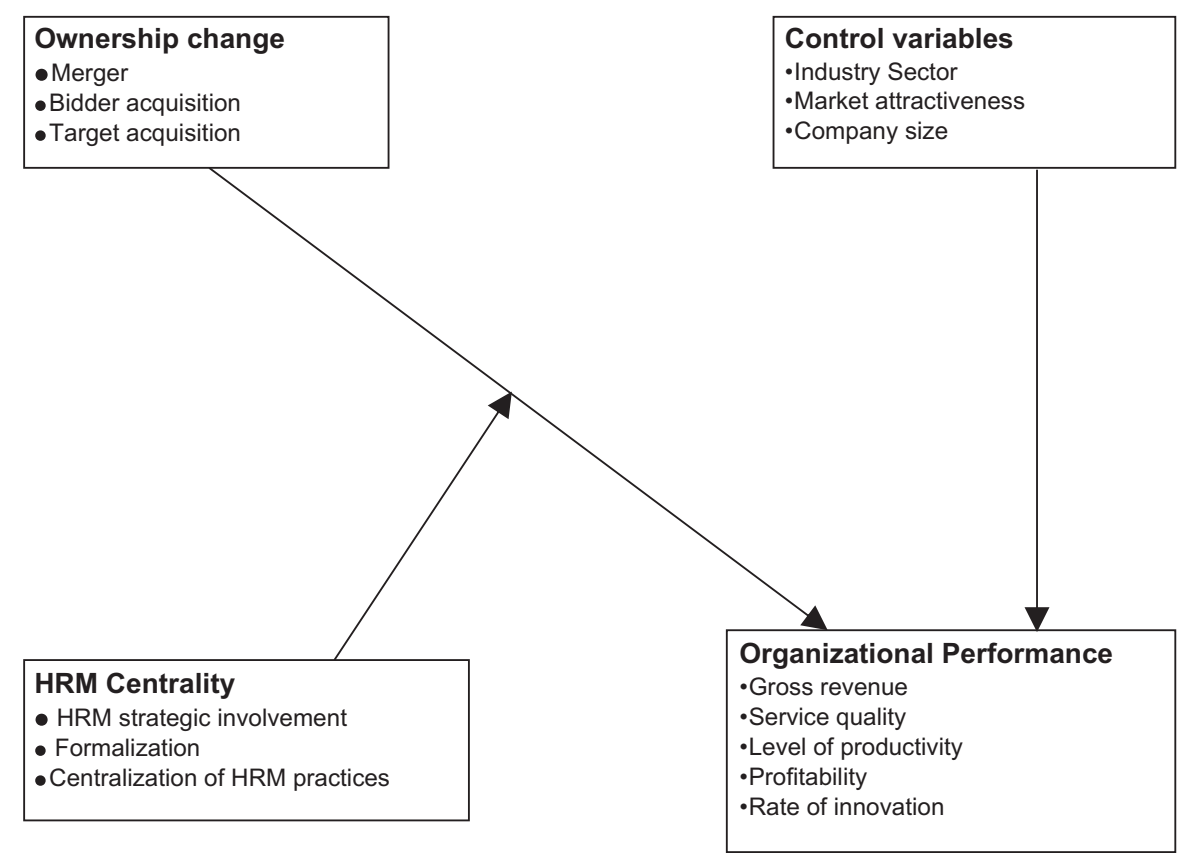

Figure 1 Conceptual framework. 
Table 1 Distribution of sample by reported histories of change (percentages).

\begin{tabular}{llllllll}
\hline Mergers (M) & Bidder acquisitions (BA) & Target acquisitions (TA) & M + BA & M + TA & BA + TA & $M+$ BA + TA & No change \\
\hline 176 & 875 & 235 & 146 & 37 & 96 & 56 & 5147 \\
$(5.56)$ & $(27.62)$ & $(7.42)$ & $(4.61)$ & $(1.17)$ & $(3.03)$ & $(1.77)$ & $(48.83)$ \\
\hline
\end{tabular}

Note: Some companies have experienced more than one type of change, represented in the table by the + sign.

Table 2 Distribution of companies experiencing mergers, bidder acquisitions, or target acquisitions, by industrial sector.

\begin{tabular}{llcc}
\hline $\begin{array}{l}\text { Industrial } \\
\text { sector }\end{array}$ & $\begin{array}{l}\text { Bidder } \\
\text { acquisition (\%) }\end{array}$ & $\begin{array}{l}\text { Target } \\
\text { acquisition (\%) }\end{array}$ & Merger (\%) \\
\hline Primary & 2.3 & 1.1 & 2.8 \\
Secondary & 47.6 & 57.3 & 37.9 \\
Tertiary & 50.1 & 41.7 & 59.3 \\
\hline
\end{tabular}

Table 3 Coding of formalization.

\begin{tabular}{lllll}
\hline & & \multicolumn{3}{c}{ Personnel/HRM strategy/ } \\
\cline { 3 - 5 } & & No & Unwritten & Written \\
\hline Business strategy & No & 1 & 2 & 4 \\
& Unwritten & 2 & 3 & 5 \\
& Written & 4 & 5 & 6 \\
\hline
\end{tabular}

the HRM Department - HRMD (1) or Line Managers - LM (0) are ultimately responsible for a given area, and a responsibility score was obtained by summing across the five areas.

Organizational performance is a single measure that includes two variables. First, gross revenue over the last 3 years, coded 5 (well in excess of costs), 4 (sufficient to make a small profit), 3 (enough to break even), 3 (insufficient to cover costs), and 1 (so low as to produce large losses). Second, rated performance on four criteria: Service quality performance, level of productivity, profitability, and rate of innovation. The ratings were given on a three-point benchmarking scale, and coded 3 (in the top 10\%), 2 (in the upper half), and 1 (in the lower half). A performance score was obtained by summing across the four criteria. In studies based on international surveys within a number of different countries, objective measures of organizational performance may be impossible to compare, given potential bias by differences in cultural orientations and fiscal regimes (Lahteenmaki \& Vanhala, 1998; Martell \& Carroll, 1995). In addition, significant correlations between subjective and objective organizational performance measures were demonstrated by Pearce, Robbins, and Robinson (1987), which supports the validity of subjective performance measures as substitutes for objective measures.

In order to condense these two variables with different measurement units (gross revenue, along a scale from 1 to 5 , and rated performance on four criteria, along a scale from 4 to 12) into one common scale, we conducted a principal component analysis, and obtained a single component of organizational performance. This is a common practice in research involving different variables measuring the same underlying dimension, and also in research on human resource management and organizational performance (e.g., Khan, 2010). In our analysis, the common factor accounted for $69 \%$ of the variance (the minimum to be extracted) in the two variables, with an eigenvalue of 1.38 for a maximum of 2 (thus passing the Guttman-Kaiser rule).

\subsection{Control variables}

Structural characteristics of industry sectors determine corporate strategies, which in turn lead to industry-specific performance differences, becoming a driver of performance variations (Porter, 1980). For these reasons, we control for industry sector (primary, secondary, and tertiary), in our analysis.

We also controlled for market attractiveness (growing, steady, or declining), which may affect organizational performance not only by forcing managers to spend more time "in the environmental threat and opportunity analysis phase of strategic planning" (Milliken, 1987:140), but also due to higher environmental munificence (Pfeffer \& Salancik, 1978). Finally, we controlled for company size, through number of people employed by the organization, since larger firms are expected to be more efficient than smaller ones (Hall \& Weiss, 1967).

Industry sector was decomposed into two orthogonal contrasts: primary versus secondary and tertiary, and secondary versus tertiary. Market attractiveness was coded 1 (growing), 0 (steady), and -1 (declining). Number of people employed ranged from 2 to 310,000 , and exhibited a highly skewed distribution. We therefore coded numbers smaller than or equal to the 10 th percentile 10 , numbers larger than the 10th percentile and smaller than or equal to the 20th percentile as 20 , and so on.

\section{Results}

A total of 3168 cases had values in all variables included in our model, and analyses will be performed with these cases only. The three variables comprising ownership change and the three variables comprising HRM centrality were mean centered to reduce multicollinearity between the independent variables in the regression including interaction terms.

The means, standard deviations, and inter-correlations of the variables are given in Table 4. Orthogonal contrasts, mean centered variables, and standardized variables, i.e., most of the variables in our analysis, have a mean of zero.

We conducted two separate multiple regression analyses with organizational performance as dependent variable, one excluding the interaction terms between organizational change and HRM, and the other including the interaction 


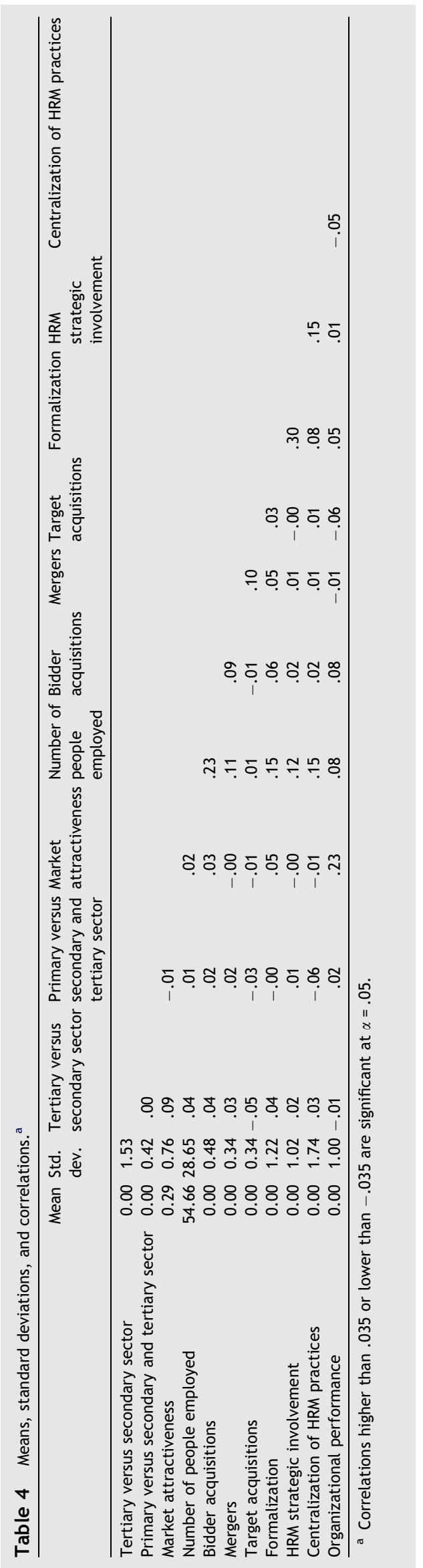

terms (to examine whether the effect of organizational change on organizational performance was moderated by HRM centrality, as predicted by hypotheses $\mathrm{H} 1, \mathrm{H} 2$ and $\mathrm{H} 3$ ). We conducted ordinary least-squares multiple linear regression analyses on a continuous dependent variable, and using as predictors either continuous variables or variables decomposed into orthogonal contrasts. An advantage of multiple regression analysis is precisely that continuous and categorical variables (properly codified) can be combined in the same analysis. A possible disadvantage is that the relation between the continuous predictors and the dependent variable may be nonlinear. We therefore inspected a plot of and the predicted values of organizational performance against standardized residuals (upon prediction), and found a homogeneous, if slightly tilted, cloud of data points, meaning that the linear assumption was not a problem.

Starting with the analysis of main effects, reported in Table 5, we first look at the impact of ownership change type on organizational performance. Results point to a statistically significant increase in organizational performance in the case of bidder acquisitions and a statistically significant decrease in the case of target acquisitions, whereas in merging companies this effect was not significant.

Our research hypotheses predict moderation effects of HRM centrality on organizational performance, in each of the three types of ownership change. Results for the interaction effects are presented in Table 6.

Our first hypothesis proposed the moderation of HRM strategic involvement on performance. Results demonstrate that the positive effect of bidder acquisitions on performance was accentuated by HRM strategic involvement, but this effect was not confirmed in the cases of target acquisitions and mergers. Hypothesis 1.b) is confirmed, but not H1.a) and H1.c).

For $\mathrm{H} 2$, concerning the moderation effect of formalization, our results partially confirm the moderating effects. In fact, as predicted, formalization accentuated the negative effect of mergers on performance, but contrary to our hypothesis, it also attenuated the positive effect of bidder acquisitions on performance; it tended however to improve the negative effect of target acquisition on performance, although not reaching statistical significance. Hypothesis 1.a) is confirmed by the results, but H1.b) and H1.c) are not.

In the third hypothesis, we argue that centralization of HRM practices in the HR department will positively moderate impact of any type of ownership change on performance. Our results show that this centralization accentuates the positive impact of bidder acquisitions on performance, but has no significant effect in the case of target acquisitions and mergers, although the sign is consistent with our predictions. In the likeness of the previous hypotheses, this hypothesis is only partially confirmed.

As to the control variables, performance increased with company size and market attractiveness. This was in fact the largest effect found. Finally, the results with the orthogonal contrasts for industry sectors show that performance was worse in the tertiary sector than in the secondary sector. 
Table 5 Regression analysis (main effects) with organizational performance as dependent variable. ${ }^{a}$

\begin{tabular}{|c|c|}
\hline & Main effects \\
\hline & Beta $t(3157) P$ \\
\hline Tertiary versus secondary sector & $-0.03-1.89 .06$ \\
\hline Primary versus secondary and tertiary sector & r $0.020 .98 \quad .33$ \\
\hline Market attractiveness & 0.2313 .09 .00 \\
\hline Number of people employed & $0.07 \quad 3.82 \quad .00$ \\
\hline Bidder acquisitions & $\begin{array}{lll}0.06 & 3.49 & .00\end{array}$ \\
\hline Mergers & $-0.02-1.22 .22$ \\
\hline Target acquisitions & $-0.06-3.29 .00$ \\
\hline HRM strategic involvement & $-0.00-0.06 .95$ \\
\hline Formalization & $0.03 \quad 1.87 .06$ \\
\hline Centralization of HRM practices & $-0.06-3.53 .00$ \\
\hline
\end{tabular}

Table 6 Regression analysis (interaction effects) with organizational performance as dependent variable ${ }^{a}$.

\begin{tabular}{lrrr}
\hline & \multicolumn{3}{c}{ Interaction effects } \\
\cline { 2 - 4 } & Beta & $t(3157)$ & $P$ \\
\hline Bidder acquisitions & & & \\
HRM strategic involvement & 0.05 & 2.56 & .01 \\
Formalization & -0.05 & -2.50 & .01 \\
Centralization of HRM practices & 0.04 & 2.26 & .02 \\
& & & \\
Mergers & & & \\
HRM strategic involvement & -0.01 & -0.70 & .48 \\
Formalization & -0.05 & -2.69 & .01 \\
Centralization of HRM practices & 0.02 & 1.28 & .20 \\
Target acquisitions & & & \\
HRM strategic involvement & 0.01 & 0.57 & .57 \\
Formalization & 0.03 & 1.43 & .15 \\
Centralization of HRM practices & 0.00 & 0.04 & .97 \\
\hline
\end{tabular}

a Incremental $R^{2}$ (interaction effects model) $=.01$,
$F(9,3148)=3.24, p=.00$.

\section{Discussion}

The aim of this paper was to examine whether HRM centrality moderated the relationship between ownership change and organizational performance. Based on the SHRM and resource based view literatures, we expected that an increase in the intraorganizational power of the HRM function would boost the impact of ownership change on organizational performance, because it would help reduce ambiguity and turbulence in the human side of the involved companies and therefore enhance motivation of managers and employees in general towards the integration. In doing so, we distinguished three different types of ownership change, and included a greater range of indicators of organizational performance than have earlier studies. Also, we decomposed HRM centrality into strategic involvement, formalization and centralization of the responsibility for specific HRM areas in the HRM department, unlike most studies reported in the literature.

Taking the main effects into consideration, bidder acquisitions generally improved organizational performance, whereas negative results were obtained for mergers and target acquisitions, which contradict the findings of previous studies that take a financial analysis approach, based on performance in the capital markets following ownership change (Datta et al., 1992; King et al., 2004). Since our data inquired about effects and outcomes on a medium term horizon, we may argue that these results encompass the consequences for organizational actors to adjust to the policies and practices of the acquiring and merging companies, frequently suffering culture clashes, downsizing and diminished career opportunities, as argued by Cartwright and Schoenberg (2006) or Larsson and Finkelstein (1999). However, the robustness of these isolated results must be established by future research.

Looking at the interaction effects, generally our findings suggest that HRM centrality moderates the relationship between ownership change and organizational performance. However, whether a greater HRM centrality was good or bad for organizational performance depended on the type of ownership change.

We predicted that formalization would boost the effect of acquisitions on organizational performance, which was refuted by the data in the case of bidder acquisitions and not significant although positive for target acquisitions. One possible explanation is to admit that the role of formalization in the integration process changes over time. In other words, in the early post-acquisition period, the integration process will be led by the bidder companies, which requires flexibility to adjust their practices to an increased and possibly more diversified workforce. Formalization in the target companies, on the other hand, may clarify HRM policies and practices, and facilitate the integration with the acquirer. However, at later stages of the integration process, as HRM policies are stabilizing around the bidder companies' practices, the moderating impact of formalization may be reversed. This argument would imply a curvilinear relationship over time which the used data did not allow us to test, and suggests a future analysis using a longitudinal design. On the other hand, in accordance to our predictions, formalization has a significant negative moderating impact on performance, in the case of mergers, where both partners share power and decision making; very formalized/rigid procedures and policies may jeopardize HRM integration and these very sensitive 'people decisions' (namely downsizing) should be shared in a diplomatic fashion and not through rigid procedures.

As expected, HRM strategic involvement was found to have a positive moderating effect on performance for bidder companies. However, the positive moderation in the merger and target acquisition cases were not revealed to be significant. We expect a more detailed analysis in further studies may unveil some of the plausible reasons for these results.

Finally, centralization of HRM practices in the HRM department was expected to positively moderate the effect change of ownership on performance, because HRM practices must be very cautious, in order to achieve synergies; for example, the HRM manager may need to negotiate the 
terms and conditions of layoffs and compensation (Antilla, 2006; Delaney \& Huselid, 1996), as well as nourish a perception of labor opportunities and security, raise expectations, support change and increase individual effort.

In addition, giving too much HRM responsibilities to line managers, in the midst of an ownership change process, can challenge their capacity to take on new roles parallel to their current workload, as Danya et al. (2008), Kirkpatrick, Davies, and Oliver (1992), McGovern, Gratton, Hope-Hailey, Stiles, and Truss (1997) argue. Our results partially confirm this prediction. In all types of ownership change, the sign of the moderation effect was positive, but it was not significant in the case of mergers and target acquisitions.

\section{Limitations}

Interpretation of the results must take the limitations of our study into account. First, we used survey data with single respondents, providing no estimate of the magnitude of error due to rater sampling (Gerhart, Wright, \& McMahan, 2000). Our results derive from questionnaires that were completed by the senior HRM manager, dated some years ago, in each company and did not include the employees' perspectives. Some of the conclusions may be biased, particularly in what concerns our concept of HRM Centrality. Future research should incorporate a multilevel analysis, to reduce the impact of any bias from a specific category. We emphasize, however, some of the practical difficulties in doing so, considering that, during processes of mergers and acquisitions, all human factor issues are politically sensitive and companies may be reluctant to participate (Cunha, 1997).

Second, because the data are cross-sectional, there may be issues in the determination of causality. Longitudinal studies could help to determine the robustness of our results, and clarify some results that remained inconclusive.

Relatedly, and in addition to the problem of the direction of causality, any causal analysis on field data must be regarded as tentative because of the potential omission of contaminating variables, which are variables that impact not only on the dependent variable, but also on one or more independent variables in the analysis (e.g., reflation or other macroeconomic indices). Contaminating variables create spurious correlations between cause and effect, and, if these variables are not controlled, these correlations are reflected in the estimated "effects" of the independent variables on the dependent variable.

For instance, one reviewer suggested that HRM centrality and organizational performance might be endogenous. We therefore looked for an instrumental variable, affecting centrality but not organizational performance in the CRANET data base, and we decided on "hierarchization," meaning whether managers, professional/technical workers, clerical workers, or manual workers are formally briefed about business strategy. The more categories are involved, or the lower the categories involved, the lower the hierarchization. We hypothesized that this variable would have an impact on HRM centrality, because, the less hierarchized the strategy decision, the more HRM strategic involvement and formalization. We instrumentalized HRM centrality, and we found no implications for the substantive conclusions drawn in this paper: the strengths of the effects, and their reliability, were almost unaffected. This analysis is obviously incomplete, but it is one illustration in which endogeneity was not confirmed.

A third limitation is that we did not use any 'accounting/ financial' performance indicator, but rather a single measure of performance that incorporated intermediate perceived indicators of performance. This is a reasonable practice, considering the Cranet data include a large number of companies in several countries, which make it impossible to compare financial indicators from companies in different sectors and across national boundaries, i.e., with different baseline values and varying applicable fiscal and tax policies. However, future studies, with a smaller number of companies, may capture more precise measures of firm performance.

Finally, there may be a statistical reason why bidder acquisitions showed such pervasive effects while mergers and target acquisitions did not. In the Cranet data we observed a moderate rate of bidder acquisitions, but low rates of mergers and target acquisitions (see Table 1). It may well be that the effects of mergers and target acquisitions could not be estimated as reliably as the effects of bidder acquisitions. Thus, conclusions about the differential impact of acquisitions and mergers should be drawn with caution.

\section{Managing M\&As - implications for practice}

The findings in our study suggest that the contribution of HRM to the management of the integration process in M\&As involves a greater HRM Centrality, albeit with some subtle differences depending on the type of ownership change.

In the case of bidder acquisitions, our results suggest that HRM strategic involvement and a shift of responsibility from line managers to HRM managers boost organizational performance. When one company acquires another one, and therefore is expected to integrate the acquired one into its policies, strategy, and culture, the human resources function has an important role as change agent, to promote and reinforce organizational transformation. Yet, looking at the target acquisition companies, it is natural that the turbulence and instability associated with the ambiguity of what is about to come, be minimized by HRM managers, through formalized HR strategies, acting as much as possible as internal consultants to top management teams.

Mergers, on the other hand, have a more delicate negotiation process in all issues affecting employees. Flexibility is needed to adjust to different situations as the integration process evolves. Our results suggest that low strategic involvement of HRM and low formalization are positive. On the other hand, centralizing HRM practices is important to promote cultural integration and to develop new skills, aligned with the strategic intent of the new emerging organization.

\section{Conclusion}

In sum, two main conclusions can be drawn from this study. First, HRM centrality moderates the relationship between ownership change and organizational performance, with different effects depending on type of change. Future research should systematically analyze these effects. 
Second, mergers and acquisitions should be considered as different change processes, mergers demanding flexibility and low formalization of HRM practices to produce better organizational results. This line of inquiry may help to better understand the puzzle of why M\&As sometimes succeed and other times fail.

\section{Acknowledgement}

The authors thank Chris Brewster and Ricardo Rodrigues, as well as the anonymous reviewers, for their comments and suggestions on earlier versions of this paper. Any possible errors are our own responsibility.

\section{References}

Agrawal, A., \& Jaffe, J. (2003). Do takeover targets underperform? evidence from operating and stock returns. Journal of Financial \& Quantitative Analysis, 38, 721-746.

Antila, E. (2006). The role of HR managers in international mergers and acquisitions: A multiple case study. International Journal of Human Resource Management, 17, 999-1020.

Becker, B. E., \& Gerhart, G. (1996). The impact of HRM on organizational performance progress and prospects. Academy of Management Journal, 39, 779-801.

Bianco, A. (2000). When a merger turns messy. Business Week, 3690, 90-93.

Björkman, I., \& Söderberg, A. M. (2003). The HR function in largescale mergers and acquisitions: The case study of Nordea. Personnel Review, 35, 654-670.

Bowen, D., \& Ostroff, C. (2004). Understanding HRM-firm performance linkages: The role of the 'strength' of the HRM system. Academy of Management Review, 29(2), 203-221.

Brewster, C., \& Larsen, H. H. (1992). Human resource management in Europe: Evidence from ten countries. The International Journal of Human Resource Management, 3, 409-433.

Brewster, C., Mayrhofer, W., \& Morley, M. (2004). Human resource management in Europe: Evidence of convergence? Oxford: Elsevier.

Buono, A. F., \& Bowditch, J. L. (1989). The human side of mergers and acquisitions: Managing collisions between people, cultures, and organizations. San Francisco, CA: Jossey-Bass.

Cartwright, S., \& Cooper, C. (1996). Managing mergers, acquisitions and strategic alliances: integrating people and cultures. Oxford: Butterworth and Heinemann.

Cartwright, S., \& Schoenberg, R. (2006). Thirty years of mergers and acquisitions research: Recent advances and future opportunities. British Journal of Management, 17, S1-S5.

Clement, M., \& Greenspan, D. (2000). Empowering human resources in the acquisition process. Glen Rock, NJ: Clemente, Greenspan \& Co.

Combs, C., Yongmei, L., Hall, A., \& Ketchen, D. (2006). How much do high-performance work practices matter? A meta-analysis of their effects on organizational performance. Personnel Psychology: A Journal of Applied Research, 59, 501-528.

Cording, M., Christmann, P., \& King, D. (2008). Reducing causal ambiguity in acquisition integration: Intermediate goals as mediators of integration decisions and acquisition performance. Academy of Management Journal, 51(4), 744-767.

Cunha, R.C. (1997). The impact of privatization on organizational culture, human resource management and individual employees. Unpublished PhD dissertation. University of Manchester Institute of Science and Technology, School of Management.
Danya, F., Guedrib, Z., \& Hatta, F. (2008). New insights into the link between HRM integration and organizational performance: The moderating role of influence distribution between HRM specialists and line managers. The International Journal of Human Resource Management, 19, 2095-2112.

Datta, D. K., Narayanan, V. K., \& Pinches, G. E. (1992). Factors influencing wealth creation from mergers and acquisitions: $A$ meta-analysis. Strategic Management Journal, 13, 67-84.

Delaney, J. T., \& Huselid, M. A. (1996). The impact of human resource management practices on perceptions of organizational performance. Academy of Management Journal, 39, 949-969.

Delery, J. (1998). Issues of fit in strategic human resource management: Implications for research. Human Resource Management Review, 8, 289-310.

DeNisi, A., \& Shin, S. J. (2004). Psychological communication interventions in mergers and acquisitions. In G. K. Sthal \& M. E. Mendenhall (Eds.), Mergers and acquisitions: Managing culture and human resources (pp. 228-253). Palo Alto, CA: Stanford University Press.

Drori, I., Wrzesniewski, A., \& Ellis, S. (2011). Cultural clashes in a "merger of equals": The case of high-tech start-ups. Human Resource Management, 50(5), 625-649.

Fairlamb, D., John, R., \& Thornton, E. (2000). This bank keeps growing and growing and.... Business Week, 3698, 134.

Gerhart, B., Wright, P., \& McMahan, G. (2000). Measurement error in research in human resources and firm performance relationships: Further evidence and analysis. Personnel Psychology, 53(4), 855-872.

Guest, D. (2011). Human Resource Management and performance: Still searching for some answers. Human Resource Management Journal, 21(1), 3-13.

Gunther, M. (2001). Understanding AOL's grand unified theory of the media cosmos. Fortune, 143(1), 72-82.

Hall, M., \& Weiss, L. (1967). Firm size and profitability. Review of Economics and Statistics, 49(8), 319-331.

Hickson, D. J., Hinings, C. R., Lee, C. A., Schneck, R. E., \& Pennings, J. M. (1971). A strategic contingencies theory of intraorganizational power'. Administrative Science Quarterly, 16(2), 216-229.

Hinings, C. R., Hickson, D. J., Pennings, J. M., \& Schneck, R. E. (1974). Structural conditions of intraorganizational power. Administrative Science Quarterly, 19(1), 22-44.

Kay, I. T., \& Shelton, M. (2000). The people problems in mergers. The McKinsey Quarterly, 4, 29-37.

Khan, M. A. (2010). Effects of human resource management practices on organizational performance - an empirical study of oil and gas industry in Pakistan. European Journal of Economics, Finance and Administrative Sciences, 24, 157-175.

King, D. R., Dalton, D. R., Daily, C. M., \& Covin, J. G. (2004). Metaanalyses of post-acquisition performance: Indications of unidentified moderators. Strategic Management Journal, 25, 187-200.

Kirkpatrick, I., Davies, A., \& Oliver, N. (1992). Decentralization: Friend or foe of HRM? In P. Blyton \& P. Turnbull (Eds.), Reassessing human resource management (pp. 131-147). Thousand Oaks, CA: Sage Publications.

Kumar, N. (2009). How emerging giants are rewriting the rules of M\&A. Harvard Business Review, 85(5), 115-121.

Lahteenmaki, S., \& Vanhala, S. (1998). HRM and company performance: The use of measurement and the influence of economic cycles. Human Resource Management Journal, 8, 51-65.

Lakshman, C. (2011). Postacquisition cultural integration in mergers and acquisitions: A knowledge-based approach. Human Resource Management, 50(5), 605-623.

Larsson, R., \& Finkelstein, S. (1999). Integrating strategic, organizational and human resource perspectives on mergers and acquisitions: A case survey of synergy realization. Organization Science, 10(1), 1-26. 
Lengnick-Hall, M., Lengnick-Hall, C., Andrade, L., \& Drake, B. (2009). Strategic human resource management: The evolution of the field. Human Resource Management Review, 19, 64-85.

MacDuffie, J. (1995). Competitive advantage through people: Unleashing the power of the work force. Administrative Science Quarterly, 40, 524-527.

Marks, M. L., \& Mirvis, P. H. (2001). Making mergers and acquisitions work: Strategic and psychological preparation. Academy of Management Executive, 15(2), 80-92.

Marks, M., \& Mirvis, P. (2011). A framework for the human resources role in managing culture in mergers and acquisitions. Human Resource Management, 50(6), 859-877.

Martell, K., \& Carroll, S. J. (1995). Which executive human resource management practices for top management are associated with higher firm performance? Human resource management, 34, 497-512.

McGovern, F., Gratton, L., Hope-Hailey, V., Stiles, P., \& Truss, C. (1997). Human resource management on the line? Human Resource Management Journal, 7, 12-29.

Milliken, F. (1987). Three types of perceived uncertainty about the environment: State, effect, and response uncertainty. Academy of Management Review, 12, 133-143.

Nikandrou, I., \& Papalexandris, N. (2007). The impact of M\&A experience on strategic HRM practices and organizational effectiveness: Evidence from Greek firms. Human Resource Management Journal, 17(2), 155-177.

Pearce, J., Robbins, D., \& Robinson, R. (1987). The impact of grand strategy and planning formality on financial performance. Strategic Management Journal, 8, 125-135.

Pfeffer, J., \& Salancik, G. (1978). The external control of organizations. New York: Harper and Row.

Porter, M. (1980). Competitive strategy. New York: Free Press.

Reeves, C., \& Edwards, T. (2009). Management strategy and HR in international mergers: choice, constraint and pragmatism. Human Resource Management Journal, 19, 24-39.

Schuler, R., \& Jackson, S. (2001). HR issues and activities in mergers and acquisitions. European Management Journal, 19, 239-253.

Stahl, K. G., Mendenhall, M. E., \& Weber, Y. (2005). Research on sociocultural integration in mergers and acquisitions: Points of agreement, paradoxes, and avenues for future research. In G. K. Stahl \& M. E. Mendenhall (Eds.), Mergers and acquisitions: Managing culture and human resources (pp. 401-411). Palo Alto, CA: Stanford Business Books.

Tregaskis, O. (1997). The role of national context and HR strategy in shaping training and development practice in French and U.K. organizations. Organization Studies, 18, 839-856.

Weber, Y., \& Drori, I. (2008). The linkages between cultural differences, psychological states, and performance in interna- tional mergers and acquisitions. In C. Cooper \& S. Finkelstein (Eds. ), Advances in mergers and acquisitions. New York, NY: JAI.

Weber, Y., \& Tarba, S. (2010). Human resource practices and performance of mergers and acquisitions in Israel. Human Resource Management Review, 20, 203-211.

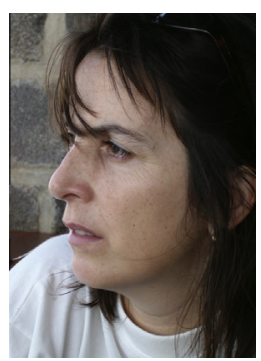

Manuela Faia Correia is Associate Professor of Management and Organizational Behavior at Universidade Lusíada de Lisboa, Faculdade de Ciências da Economia e da Empresa, Lisbon, Portugal. She received her Ph.D. in Industrial and Business Studies at University of Warwick, United Kingdom. Her research focuses on emergent processes of organizing, human resource effectiveness and new technologies.

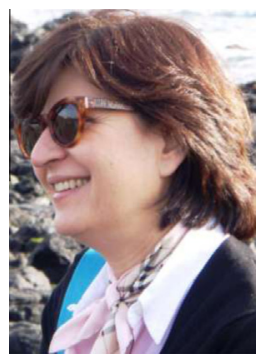

Rita Campos e Cunha has a PhD in Management from the University of Manchester Institute of Science and Technology-UMIST. She is Associate Professor of Human Resource Management and Organizational Behavior at the Nova School of Business and Economics, Portugal. Her research interests currently include HRM strength and organizational performance and impact of downsizing on highly qualified professionals. She has published in several management journals.

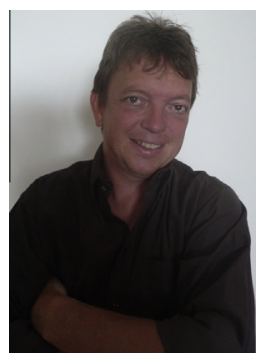

Marc Scholten received his PhD from Tilburg University in The Netherlands, and is currently Associate Professor with Habilitation at the ISPA University Institute in Portugal. He is active in the area of Behavioral Decision Making and Behavioral Economics. His research interests include intertemporal choice, risky choice, and context effects, all with an emphasis on quantitative modeling. He had published in journals like Psychological Review, Journal of Experimental Psychology: General, Management Science, and Organizational Behavior and Human Decision Processes. 